\title{
Credibilidad testimonial del testigo en el proceso penal
}

\section{Witness testimonial credibility in criminal proceedings}

\author{
Rafael Ayala Yancce ${ }^{1}$ \\ Universidad Alas Peruanas - Perú \\ ayalayancce_25@hotmail.com \\ https://orcid.org/0000-0002-1517-5132
}

\begin{abstract}
Resumen: Hoy en día la gran mayoría de los jueces para valorar la credibilidad testimonial dentro del proceso penal como primer punto analizan las características personales y los cambios fisiológicos del testigo, dejando a un lado la funcionalidad de la memoria humana. La psicología del testimonio nos precisa que para valorar la credibilidad no tiene por qué examinar las características del testigo, sino que debe analizarse la correspondencia entre lo sucedido y lo que manifiesta el testigo de lo que ha percibido, ya que esto permite diferenciar entre las experiencias vividas de aquellas historias imaginadas o inventadas. El objetivo del presente artículo es analizar la exactitud de la memoria a la hora de reproducir la información. Una vez analizada la exactitud de la memoria y las fallas en la recuperación de la información me centraré en presentar los pasos o criterios de valoración de la credibilidad testimonial de los testigos presenciales y referenciales que debe tener en cuenta el juez a la hora de motivar la sentencia.
\end{abstract}

Palabras-clave: Memoria; credibilidad; testimonio; testigo presencial, testigo referencial.

ABSTRACT: Nowadays, the great majority of the judges to assess the credibility of the testimonies within the criminal process as a first point analyze the personal characteristics and physiological changes of the witness, leaving aside the functionality of human memory. The psychology of the testimony tells us that in

1 Docente auxiliar de la Universidad Alas Peruanas/Perú. Abogado litigante, con estudios de maestría en curso en ciencias penales. 
order to assess credibility, it is not necessary to examine the characteristics of the witness, but rather that the correspondence between what happened and what the witness manifests from what he has perceived must be analyzed, since this allows us to differentiate between the experiences lived from those imagined or invented stories. The objective of this article is to analyze the accuracy of the memory when reproducing the information. Once the accuracy of the report and the failures in the recovery of the information have been analyzed, I will focus on presenting the steps or criteria for assessing the testimonial credibility of the eyewitnesses and referential witnesses that the judge must take into account when motivating the judgment.

KEYwoRDs: Memory; credibility; testimony; eyewitness; referential witness.

CONTENIDO: Introducción; 1. La memoria; 1.1. Memoria sensorial; 1.2. Memoria a corto plazo; 1.3. Memoria a largo plazo; 1.4. Fallas en la recuperación de la información; 2 . Credibilidad del testimonio; 3. Concepto de testigo; 4. Clases de testigo: 4.1. Testigo presencial; 4.1.1 Criterios para evaluar la credibilidad testimonial del testigo presencial; 4.2. Testigo de referencia o de oídas; 4.2.1. Criterio para evaluar la credibilidad del testimonio del testigo referencial; Consideraciones finales; Referencias bibliográficas.

\section{INTRODUCCIÓN}

La psicología del testimonio viene estudiando, por más de una década la exactitud de lo que manifiesta el testigo a la hora de reconstruir lo que ha percibido a través de sus sentidos, es decir, la preocupación de hoy en día es, si realmente el testigo sea presencial o referencial está contando lo que realmente ha percibo u oído o simplemente está inventado o creando historias falsas.

Algunos estudios realizados por la ONG norteamericana Innocence Project, ha demostrado que el $80 \%$ de las condenas a inocentes tiene como base la identificación errónea de parte de las víctimas y testigos, tal es el caso de Rafael Ricardi Robles, quien fue identificado por la víctima en una rueda de reconocimiento como su agresor, siendo condenado a 18 años de pena privativa de libertad, por la Sección Quinta de la Audiencia 
Provincial de Cádiz-España, por el delito de violación sexual; luego de 13 años de prisión el 25/07/2018 el sentenciado fue liberado tras haberse probado su inocencia.

Otro de los casos, es de Julio Robles, quien fue puesto en set fotográfico por la Policía, oportunidad en que fue reconocido por la víctima como responsables del robo con violencia, delito por el cual fue condenado 5 años de pena privativa de libertad; luego de 459 días encarcelado el 14/01/2014 fue liberado tras haber probado su inocencia en la Corte Suprema de Copiapó-Chile. Por su parte, los estudios recogidos por (Ferrer; Dieuzeide, 2018: 1) en el año 2,014 se demostró que la totalidad de declaraciones de los testigos que habían identificado en forma inequívoca a los acusados de haber sido autores de los delitos cometidos el $40 \%$ ha dado a lugar a condenas erróneas, pese a que los testigos en forma categórica han señalado estar seguros de lo que han manifestado.

La pregunta que surge es: ¿por qué creer al testigo presencial de lo que dice haber visto?, ¿ ¿ómo sabemos si el testigo presencial miente o simplemente narra los hechos desde sus propias experiencias?, ¿la calidad de información que proporciona el testigo presencial y referencial realmente es exacto a lo que ha visto u oído?, ¿existe algún método o paso para valorar correctamente la credibilidad del testimonio?, ¿es exacto la memoria a la hora de recuperar la información?. Estas cuestiones serán tratadas, a partir de la psicología del testimonio ${ }^{2}$.

Teóricamente la credibilidad testimonial es definida como valoración subjetiva de la exactitud estimada de las declaraciones de un testigo (Manzanero, 2008: 179), es decir es la correspondencia entre lo sucedido y lo que manifiesta el testigo, es ahí donde no se toma en cuenta las características personales del testigo, ya que esta no permite hacer una diferencia entre la experiencia vivida de aquellas historias imaginadas o inventadas.

El objetivo general del presente artículo es precisamente analizar la correspondencia entre los hechos ocurridos y lo que recuerda el testigo a la hora de reconstruir la información, ya que en este último es donde la información sufre diferentes variaciones o transformaciones, por la

2 Para su mejor estudio, véase a Mazzoni, 2019, Diges, 2018, Manzanero, 2008 y Ramos, 2018. 
presencia de factores como: el transcurso del tiempo, la presencia de sugestión y la autosugestión, así como determinar los criterios o pasos que debe tener en cuenta el juez a la de hora valorar la credibilidad testimonial de los testigos presenciales y referenciales.

\section{LA MEMORIA}

La memoria es la congregación de pensamientos, es la madre de donde mana el pensamiento (Heidegger, 2005: 22), gracias a ella el hombre hemos podido evolucionar y sobrevivir en el tiempo (Mazzoni, 2019: 65), "ya que nos ha permitido aprender de nuestras [propias] experiencias”, las mismas que nos sirve como eje central para construir nuestra personalidad.

Siendo así, en el proceso penal a lo largo de los años hemos internalizado erróneamente que la memoria de las personas o mejor dicho de los testigos almacenan la información percibida con exactitud como si fuera una cámara de vigilancia y reproduce el hecho fenomenológico tal como ocurrió en la realidad, sin embargo, dicha afirmación es incorrecto puesto que la memoria se encarga de almacenar información seleccionada, "interpretada y codificada de muy diferentes formas en virtud de la información previa que una determinada persona posea" (Manzanero, 1991: 7), proceso donde lo percibido está sujeto a las transformaciones y alteraciones (Hoffding, 1926: 194), por la presencia “nuevas impresiones".

Wells y Lindsay (1983), Schooler, Gerhard y Loftus (1986) y Lindsay, Lim, Marando y Cully (1986), precisan que para evaluar la credibilidad del testimonio se debe conocer la funcionalidad de la memoria o mejor dicho la metamemoria ${ }^{3}$ del testigo, ya que en el proceso de percepción interviene varios factores como: predisposición, intensidad, luminosidad, movimiento, contexto social, nivel de atención, estado emocional, intervalo de tiempo, etc., factores que son determinantes para la selección y su posterior almacenamiento de la información.

3 Se puede definir como los procesos de auto-observación de las habilidades de memoria, lo que incluiría cualquier tipo de conocimiento que posea la persona sobre su memoria. (Mira, Diges, 199: 50). 
Lo cierto es que no todo lo percibido por los sentidos son almacenados en forma de recuerdos en la memoria episódica sin alteración alguna, sino por el contrario la información retenida con el paso del tiempo se deteriora de a poco; es decir, la memoria va dejando la información en forma de olvido. En otras palabras, el transcurso del tiempo deteriora los detalles de la información almacenada, haciendo muchas veces imposible de recordar los detalles del hecho fenomenológico. "Así pues, un recuerdo de un suceso real podría "desaparecer" en favor de otro" (Manzanero, 1991: 7) y, otras veces, puede ocurrir que las cosas se consideren que ocurrieron de una determinada manera, porque es lo que "suena familiar" (Cabeza; Kim, 2007: 12190), ya que muchas veces las personas solemos construir la información a partir de nuestras propias experiencias.

Para tener un enfoque más claro de lo que se ha dicho hasta aquí, importa conocer la funciónabilidad de la memoria humana diseñado por Atkinson y Ahiffin (1968), para quienes la memoria humana está compuesta por tres componentes básicos como: la memoria sensorial, la memoria a corto plazo y la memoria a largo plazo; estos tres componentes tienen una conexión secuencial indivisible, puesto que una depende de la otra, basta que una de ellas este ligeramente dañado; la funcionabilidad de la memoria se ve comprometido en sus funciones esenciales de recepción, codificación, retención y recuperación de la información. Para comprender estos últimos es necesario realizar un desarrollo de cada uno de los componentes.

\subsection{Memoria Sensorial}

La memoria sensorial "se encarga de detectar información aportada por las cosas que les rodean” (Haack, 1993: 292). Esto es, se encarga de percibir las sensaciones que se producen en el mundo exterior, las mismas que permanecen por un tiempo muy limitado, tal como sostiene Neisser (1967) citado por (Manzanero, 2008: 32); es decir, la información obtenida por parte del testigo presencial permanece por fracción de segundos; posteriormente estos datos pasarán por un proceso de codificación y selección, puesto que algunos de los datos 
serán desechados por la propia memoria, mientras que las otras serán enviadas a la memoria de corto plazo.

Es preciso señalar que la captación de la información por parte del testigo presencial depende del nivel visual, la distancia entre el testigo y la ocurrencia del evento criminal y otros factores como: la velocidad, duración del evento criminal, edad del testigo, el nivel de estado emocional etc., tal como describe (Ramos, 2018: 100-104); estos indicadores generan fallos en la capacidad de percepción y su posterior recuperación de la información por parte de los testigos presenciales, por ejemplo un testigo presencial con deficiencias visuales tendrá la capacidad limitada de captar la información con mayores detalles contextuales y sensoriales como tal realizará una reconstrucción fraccionada o incluso con añadiduras de otros datos que nunca ha ocurrido en la realidad.

Las máximas de la experiencia indica que el evento criminal tiene una duración breve; lapso en que el testigo presencial tendrá la oportunidad de captar los detalles contextuales como el tiempo, lugar, colores, olores, sonidos etc., sin embargo, toda esta información permanecerá por un breve tiempo, "hasta que se desvanece sola unas fracciones de segundos después” (Manzanero, 2008:32), ya que algunos detalles serán desechados por su irrelevancia o insignificancia para el testigo, por lo que, no toda la información pasará a la memoria de corto plazo, de modo que el gran problema radica en la capacidad de percepción del testigo.

\subsection{MEMORIA A CORTO PLAZO}

Ahora bien, la memoria a corto plazo (MCP) en adelante, es el encargado de codificar la información trasmitida por la memoria sensorial -visual, espacial y verbal-. Esto es, "actúa como una memoria de trabajo" (Baddeley, 1998: 80), puesto que toda información que ha percibido el testigo presencial en la escena del crimen es transferida a la MCP donde se mantendrá por un periodo muy breve de 15 a 20 segundos; durante esta fase, la memoria no se detiene en sus funciones, sino por el contrario, continúa pensando o recepcionando otras informaciones provenientes de la memoria sensorial. "Así que la MCP tiene dos tareas principales: almacenar brevemente la nueva información y trabajar en 
ella" (Morris; Maisto, 2009: 239); es decir, la MCP se encarga decodificar $\mathrm{y}$ dar significado a lo que ha percibido sensorialmente.

Por otro lado, los estudios científicos han demostrado que la MCP, tiene capacidad limitada de almacenar lo percibido en forma visual, ya que su "capacidad [de] retener estímulos auditivos es superior [que] visuales” (Manzanero, 2008: 35). Si analizamos la declaración testimonial teniendo en cuenta lo señalado por Manzanero, me temo que estamos ante un problema muy complejo, puesto que un testigo de oídas con deficiencias -auditivas- tendrá dificultad para oír lo que realmente está contando el emisor, si a esto sumamos la falta de atención, las condiciones del lugar y la presencia de los agentes perturbadores que impiden la correcta escucha por parte del testigo referencial; este captará una información pobre; y, a partir de allí su MCP comenzará codificar la información con serias alteraciones.

\subsection{MEMORIA A LARGO PLAZO}

Ahora bien, esta parte de la memoria para almacenar la información procedente de la MCP utiliza dos fuentes, las mismas que vienen a ser: la memoria semántica y la memoria autobiográfica o episódica propuestos por Squire y Cohen (1984) y Tulvin (1972).

La memoria semántica tiene como función recuperar conocimiento cognitivo general, "perdiendo completamente lo relativo a las coordenadas espacio-temporal de que se ha aprendido" (Mazzoni, 2019: 66). Visto así aparentemente no tendría ningún tipo de participación en el campo de la psicología del testimonio, lo cual es erróneo puesto que la memoria semántica tiene un papel trascendental, ya que permite ubicarnos en el tiempo y espacio, es donde todo lo percibido semántica y visualmente está interpretada y codificada ${ }^{4}$ “en

4 La codificación hace a cada huella de la memoria circunstancial y específica, de forma que pueden existir tanta como codificaciones diferentes se realicen. (Manzanero, 2008: 38). Por su parte Stein; De Ávila (2015: 9), precisa que la codificación depende de cómo la persona perciba el evento y esta percepción está influenciada varios factores presentes en el momento del evento, como la atención, la excitación fisiológica de la persona en ese momento, la visión en qué posición vio el evento. 
términos de significado" (Morris; Maisto, 2009: 242). En otras palabras, la memoria semántica se encarga de interpretar y dar significado a las experiencias vividas y "como tal interactúa como organizador y andamio para estructurar y representar los conocimientos en la [Memoria a largo plazo (MLP) en adelante]" (Mazzoni, 2019: 70). Esto es, la MLP actúa como la biblioteca, donde nuestros recuerdos están registrados como huella de memoria.

La memoria episódica o autobiográfica, es el lugar donde se almacena todas nuestras las experiencias, es "[por ello] que interviene en las declaraciones de los testigos" (Manzanero, 2008: 38), ya que en esta parte de la memoria está registrado los recuerdos en forma de -huellas de memoria- las mismas que está integrado por la información central estructurado semánticamente, que permanecen retenidos por un periodo largo, sin embargo, estas huellas de la memoria no permanecen intactos, sino que el transcurso del tiempo es un factor que degrada "los detalles menos consistentes con el esquema general” (Diges, 2018: 23), por lo mismo, la propia memoria se encarga de recrear la información con datos preexistentes a la hora de recuperar la información.

Otro factor que tiende a modificar o transformar las huellas de la memoria, de acuerdo a los estudios realizados por Tulving (1983), es el proceso de recodificación que ocurre después del proceso de codificación de la información original; fase donde la información original sufre ciertas modificaciones, debido a las actividades mentales propios del hombre, sobre todo cuando la información transmitida por la MCP del testigo presencial o referencial corresponde a situaciones similares, que posteriormente producirá recuerdos falsos.

\subsection{FaLlas EN LA RECUPERACIÓN DE LA INFORMACIÓN}

Hemos advertido que la memoria no es una cámara de vigilancia que pueda captar y registrar al milímetro todos los detalles percibidos, sino por el contrario, registra únicamente ciertos detalles relevantes en la memoria episódica, que posteriormente será recuperado a través del proceso de reconstrucción; proceso en que muchas veces "coloreamos y damos forma a nuestras experiencias de vida basadas en lo que sabemos sobre el mundo" (Izquierdo, 2011: 36); en este proceso de reconstrucción la 
memoria tienden a sufrir [interferencias positivas y negativas], no solo en el sentido de disminuir su agudeza, sino en el sentido de "crear" "hechos" que nunca sucedieron (Ramos, 2018: 110), puesto que la memoria puede ser modificada (Mazzoni, 2019: 75), facilmente en forma consciente o inconcientemente por efecto de información engañosa procedentes del mundo exterior.

Existen factores que de una $\mathrm{u}$ otra forma interfiere en la recuperación de la información como por ejemplo, el trascurso del tiempo ${ }^{5}$, la forma de realización de preguntas ${ }^{6}$, información post-del evento criminal, etc., factores que tienen mucha influencia en la recuperación de la información, toda vez que los testigos en la práctica son llamados a declarar pasado un lapso de semanas, meses e incluso años, momento en que el testigo proporcionará información sesgada o contaminada muchas veces inexistente a los que se le denominada -falsas memorias-, puesto que la memoria a la hora de reconstruir la información utiliza las inferencias analógicas (Mazzoni, 2019: 75). En la misma linea "los psicólogos experimentales favorecieron la opinión de que el tiempo simplemente se correlaciona con algunos otros factores que causa el olvido" (Baddeley, 2010: 215), además [el] deterioro gradual de la memoria con el tiempo aumenta las posibilidades de que se contamine, ya sea internamente o externamente, produciendo recuerdos falsos (Stein; Ávila., 2015: 21-22).

Para evitar la introducción de los recuerdos falsos (Di Gesu, 2010: 173-174), sugiere "que [la recolección del tetimonio debe ser] oportuna, ya que es la única forma de evitar el clima del (olvido), la influencia de opiniones, críticas y sugerencias de familiares, vecinos y amigos (en ciertos casos, incluso de medios de comunicación)”. Lo sugerido por Di Gesu, podría ser cierto, pero debemos tener presente que en un proceso penal acusatorio, las declaraciones testimoniales serán valorados como prueba

5 Toda vez que la función de la memoria humana es dinámica que va almacenando nuevas informaciones captadas por los sentidos, las mismas que van interfiriendo su recuperación de la información.

6 El gran problema mediante el cual se contamina la información, es a través de realización de preguntas sugestivas empleadas en el interrogatorio por parte de los abogados, fiscales hasta por los propios psicólogos, mediante las cuales se introduce falsos recuerdos. 
una vez que estas hayan sido actuadas en un proceso contradictorio, ante un juez de juzgamiento, por lo que, todas las declaraciones recabas a nivel policial y fiscal tiene como finalidad "apoyar la formulación del enjuiciamiento ante el juez” (Ávila, 2013: 55), es decir las testimoniales recabadas a nivel policial y fiscal constituye unicamente como elementos de convicción que permite al fiscal formular una acusación contra el imputado.

\section{Credibilidad del testimonio}

En principio, la credibilidad puede ser definida como valoración subjetiva de la exactitud estimada de las declaraciones de un testigo (Manzanero, 2008: 179), sin embargo, debemos hacer una distención entre la exactitud del testimonio y la credibilidad del testigo, este último es la correspondencia entre lo que ha ocurrido y lo que relata el testigo, en otras palabras, está asociado a la credibilidad de testigo como persona; mientras tanto, la exactitud del testimonio implica la correspondencia entre lo ocurrido y lo captado por la memoria. Esto es, "si los sucesos descritos en la declaración corresponden a los hechos realmente vividos" (Offe, 2000: 12).

La determinación de la credibilidad se ha convertido en una preocupación en el mundo de la psicología del testimonio, por ello, surgieron diferentes corrientes que han planteado diferentes métodos para determinar la credibilidad del testigo, entre ellas tenemos: Los cambios de conducta y los cambios fisiológicos.

El primero, se presenta cuando el testigo a la hora de ser sometida a una interrogación, por parte de fiscales, abogados y jueces sufre diferentes cambios conductuales, por ejemplo el sonrojecimiento, el tartamudeo, movimientos corporales, posición corporal, sudoración, etc., estos signos hoy en día sirve para evaluar la credibilidad testimonial, sin embargo, es un grave error que conduce a errores judiciales, debido a que es perfectamente que un testigo que es llamado por primera vez en su vida a una declaración presente estas manifestaciones fisiológicas, por la presencia de personas desconocidas y por el propio ambiente donde es interrogado.

El segundo, consiste en la aplicación de varios instrumentos entre ellas tenemos el polígrafo, instrumento denominado también como 
detector de mentiras, que a medida que el entrevistado va respondiendo las preguntas, tiende a detectar cambios o alteraciones fisiológicos como incremento de la tasa cardiaca, incremento de ansiedad, dilaciones pupilares, etc., sin embargo, detrás de este método existen muchos detractores quienes sostiene que este instrumento "sirve únicamente para descubrir conocimientos que tiene en relación con el crimen, pero no si lo cometió realmente" (Querejeta, 1999: 160), por lo que, un testigo con altas niveles de ansiedad es pasible de ser considerado como un testigo deshonesto.

Frente a estas deficiencias que representan el uso de estos instrumentos o métodos; en la actualidad la psicología del testimonio nos ha planteado otro método, que en mi opinión proporciona grades beneficios en la práctica judicial. Esto es, la preocupación actual de la psicología del testimonio no es principio el estudio de las características personales, cambios conductuales y los cambios fisiológicos que presenta el testigo, sino se debe focalizarse en "el contenido de la manifestación" (Manzanero; Diges, 1993: 2). Esto es, se debe examinar la correspondencia entre lo sucedido y lo que manifiesta el testigo, sin tener en cuenta las características personales del testigo, ya que esta no permite hacer una diferencia entre la experiencia vivida de aquellas historias imaginadas o inventadas.

Por lo que, para la valoración de la credibilidad del testimonio es preciso "no atribuir de manera automática una credibilidad o exactitud mayor al detalle recordado por dos testigos que al detalle que sólo es aportado por uno, puesto que la coincidencia podría ser producto de un interrogatorio inadecuado" (Diges, 2014: 29), así como podría obedecer a factores de sugestión y autosugestión.

\section{Concepto de testigo}

Testigo es aquella persona que ha presenciado la realización del hecho fenomenológico a través de sus sentidos ya sea en forma directa o indirecta. En términos jurídicos podemos decir que el testigo es aquella persona que ha presenciado a través de sus sentidos la ocurrencia de los hechos jurídicamente relevantes. "En consecuencia - y en principio - los 
testigos concurren a declarar sobre los hechos" (Baytelman; Duce, 2016: 60), que han percibido ante la Policía, Ministerio Fiscal o ante un juez de la causa.

Por lo que, el testigo únicamente está llamado estrictamente a narrar todo aquello que ha experimentado o percibido sus sentidos, más no está obligado a transmitir sus propios juicios de valor, creencias o experiencias personales mucho menos sus propias valoraciones (Jauchen, 2014: 286). Por lo tanto, todos los testigos que tiene la información útil para el proceso son hábiles para declarar, puesto que en un sistema acusatorio "desaparece las instituciones procesales de tachas contra los testigos" (Baytelman; Duce, 2016: 60).

\section{Clases de testigo}

\subsection{Testigo PRESENCIAL}

Es aquella persona que en forma directa ha presenciado o experimentado la realización del hecho fenomenológico de carácter delictuoso. Esto es, el testigo ha percibido a través de sus sentidos la ocurrencia de un evento criminal, oportunidad en que pudieron haber retenido los detalles contextuales y sensoriales, por ejemplo, las características personales y circunstancias del lugar, tiempo y modo en que ocurrió los hechos delictuosos.

El gran problema que viene generando discusión a nivel del proceso penal es, si realmente el testigo presencial al momento de declarar sobre lo que ha experimentado o percibido sus sentidos obedecen a la verdad histórica ${ }^{7}$, es decir, si lo que dice el testigo es exacto a los hechos

7 Sobre este punto debemos precisar que la verdad únicamente es una construcción social, puesto que no se puede determinar científicamente la verdad, incluso la ciencia trabaja en base a las aproximaciones aceptadas por la comunidad científica, por ejemplo, un médico que ha detectado un cáncer terminal en un paciente, no podrá precisar las causas o el origen del cáncer, sino lo que el médico dará a conocer son las causas probables que dio origen al cáncer. En la misma línea (Haack, 2008: 573) nos precisa que la verdad "no depende de lo que nosotros creemos o aceptamos, no es relativa a la 
ocurridos o no; para cuyo efecto hay que tener en cuenta los procesos psicológicos que interviene como la percepción, el nivel de atención y los factores señalados en el punto 1.1.

Como hemos advertido líneas arriba la memoria aparte de ser tan complejo, es "difícil de describir y de conceptualizar" (Petisco, 2016: 79), de tal suerte que no siempre capta todo lo que ha percibido sus sentidos, sino una parte de ella que será procesada por la memoria sensorial, la misma que se encargará de transferir a la MCP y posteriormente es almacenada en la memoria episódica, donde finalmente permanece en forma de recuerdo o mejor dicho en forma de huellas de memoria que está codificada semánticamente.

Un testigo por más que tenga una buena memoria no tiene la posibilidad de captar, retener y recordar la información de todo aquello que ha experimentado o percibido a través de sus sentidos, precisamente por los factores señalados en el punto 1.1, por lo que, a la hora de declarar no puede reproducir la información al milímetro con todos sus detalles contextuales de lo que dice haber visto; puesto que el paso del tiempo "[...] ya supone un fuente de degradación y contaminación del testimonio" (Diges, 2018: 23), o simplemente la propia memoria hace que ese recuerdo se pierda en forma progresiva, porque la información almacenada no es de uso frecuente en sus actividades diarias de la persona; o que dicho recuerdo genera en la persona inestabilidad emocional.

Otro de los factores, que contamina la declaración testimonial es la presencia de la sugestión que tiende a "[reflejar] una combinación de cambios basados en la memoria [episódica de los testigos]" (Memon; Bull, 2003: 93); incluso tiene el poder de conllevar a modificaciones irreversibles de la memoria. (Mazzoni, 2019:77). La modificación de las huellas de la memoria, en la práctica judicial se produce con frecuencia en la forma de interrogación por parte de los fiscales, abogados y psicólogos quienes a diestra y siniestra realizan preguntas sugestivas a los testigos,

cultura, a la comunidad, a una teoría o a un individuo; y no es una cuestión gradual, ni una conglomeración de propiedades que pueden estar total o parcialmente satisfechas". 
con la finalidad de introducir información falsa ${ }^{8}$, puesto que "los recuerdos son [mucho] más fácil de modificar" (Loftus, 1997: 71).

Por otro lado, aunque parecieran ilógicas las personas solemos construir un recuerdo a través de la autosugestión a partir de las huellas de la memoria. Esto es, la propia memoria se encarga de recrear la información con datos análogos o semejantes previamente almacenadas en memoria episódica. En concreto, incorpora detalles de lo que debiera haber habido en ese contexto, detalles que tiene una alta probabilidad de ocurrencia en un ambiente determinado (Diges, 2018: 184), sin embargo, estas inferencias lógicas pueden distorsionar la exactitud de la memoria.

\subsubsection{Criterios para evaluar la credibilidad testimonial del testigo PRESENCIAL.}

\subsubsection{LA COHERENCIA COMO PRIMER PASO DE LA EVALUACIÓN DE LA CREDIBILIDAD}

En principio, la coherencia es la consistencia lógica que funciona como una "restricción para la adquisición de creencias, que nos empuja a ser selectivos acerca de qué testimonio aceptamos [y qué testimonios no]" (Lipton's, 2001: 23). Siendo así, la declaración testimonial será “articulada en términos explicativos [posibles]" (Lipton's, 2001: 23), cuando el testimonio está organizada y estructurada desde un punto de vista racional.

Entonces, la coherencia obliga que el contenido de la declaración esté plenamente conexo y estructurado en términos explicativos posibles entre un suceso con otra, que permita reconstruir la historia con exactitud posible a lo que ha ocurrido, de modo que "será más coherente cuando las diferentes partes del suceso complejo están relacionadas de forma lógica entre sí confirmándose unas a otras, de forma que definan el mismo suceso". Trankell citado por (Manzanero, 2001: 57); es decir una parte de los datos o información que contiene la declaración debe estar

8 Esto es, el testigo introduce un dato que nunca ha ocurrido en la realidad. Sobre el particular (ver Diges, 2018:23). 
conectados en forma secuencial como si fuera una cadena que juntados todas ellas forme una hipótesis completa que nos permita justificadamente afirmar la verdad'.

Debemos dejar en claro que la declaración testimonial puede ser muy coherente sin contradicciones, esto no significa que la declaración sea exacto, es decir, obedezca a los hechos realmente percibidos o experimentados, sino es un signo de que el testigo ha sido preparado por los propios abogados y fiscales, así como puede haber declaraciones testimoniales contradictorias en su estructura interna y externa; esto tampoco significa que el testimonio sea falso, sino por el contario, dichas contradicciones pueden obedecer factores del transcurso del tiempo y la presencia de la sugestión que contamina y crea recuerdos falsos en la memoria.

Por lo que, la coherencia no es sinónimo de "perfección, sino es una mera consistencia" (Blanshard, 2001: 107), que tampoco obedece a planteamientos científicos (Joaquín, Diges, 1991: 50), por lo que, a la hora de valorar la credibilidad del testimonio lo único que debe hacer el juez es tener como un dato objetivo que debe describir el conjunto de los testimonios, reconstruyendo un esquema general de lo que ha señalado el testigo, la misma que debe estar descrita en la motivación de la sentencia.

\subsubsection{LA CONTEXTUALIZACIÓN COMO SEGUNDO PASO DE LA EVALUACIÓN DE LA CREDIBILIDAD}

La contextualización consiste en que el testigo presencial que realmente ha percibido o experimentado la ocurrencia de un hecho fenomenológico eventualmente podría reproducir la historia con mayores detalles contextuales y sensoriales de tiempo-espacio, puesto que su origen radica en memoria externa. Esto es, "presenta una mayor cantidad de información contextual, sensorial (olores, colores, sonidos...)” (Soto,

9 Entonces, el contenido de la declaración con una construcción lógica es un enunciado que produce mayor probabilidad a lo realmente percibido a través de los sentidos, de modo tal que "la coherencia de la declaración se refuerza en su espontaneidad, en su ausencia de contradicciones”. SC18595-2016 27/11/2016 de Colombia. 
Ruiz y Llor, 2013: 6), ya que estuvo en el preciso momento en que ocurrió el evento criminal.

Incluso la experiencia señala que el testigo presencial que ha percibo directamente el evento criminal, debería haber retenido también el tipo de detalles que la gente suele retener en ese tipo de situaciones (Baytelman; Duce, 2016: 176). Lo dicho por el autor puede ser cierto, sin embargo, la memoria episódica no retiene todos los detalles contextuales y sensoriales de lo que ha percibido, sino por el contrario,el transcurso del tiempo y la presencia de la sugestión degrada y contamina las huellas de la memoria que "incluso puede añadir datos que encajan en la idea general que nunca sucedieron" (Diges, 2018: 23), pero también se puede crear falsos recuerdos cuando el testigo reconstruye la información utilizando la autosugestión. Esto es, el propio testigo puede reconstruir la información dotando de sentido lógico y coherencia a lo que cuenta pese a que los hechos no sucedieron de la forma que cuenta.

Prueba de ello es que los testigos presenciales, frente al olvido de los detalles menos consistentes pueden llegar a "crear falsos recuerdos [que] son construidos por combinación de recuerdos reales con el contenido de las sugerencias recibidas de otros" (Loftus, 1997: 75). "Algunas veces, [los testigos] recuerdan algo que fue olvidado; tales olvidos y recuerdos no significa una represión y contrarepresión, más bien significa que algo de últimamente recordado pueda reflejar memorias auténticas, [por ello se debe] sondear la credibilidad, tiempo, motivos, sugestión potencial, pruebas y otros rasgos" (Loftus, 2000: 36). Por lo tanto, el dato de la contextualización es otro de los datos objetivos al igual que la coherencia que el juez en su motivación de la sentencia válidamente puede referirse si el testigo ha contextualizado los detalles o no y en qué medida es creíble dicha contextualización.

\subsubsection{LOS ACUERDOS INTERSUJETO O LA LLAMADA CORROBORACIÓN} PERIFÉRICA COMO TERCER PASO DE LA EVALUACIÓN DE LA CREDIBILIDAD

En principio, "los acuerdos intersujetos hace referencia a la consistencia entre las declaraciones suministradas por dos o más testigos” (Manzanero, 2008: 181), en otros términos, la versión de un testigo está corroborada con otra manifestación o con otros datos que, indirectamente 
acredita la veracidad de lo que manifiesta el primero. En la práctica judicial muchos de los jueces de hoy en día, para evaluar la credibilidad de los testigos ven como punto partida la confianza con que manifiestan sobre los hechos y las características personales, empero, como hemos dicho esto debe descartarse por completo de la práctica judicial y como tal debe enfocarse en el contenido de la declaración, ya que los signos de expresiones no verbales son irrelevantes para efectos de evaluar la credibilidad testimonial, puesto que dichas expresiones en modo absoluto "son signos de fiabilidad para distinguir [...] entre la verdad y la mentira ${ }^{10 "}$ (Diges, 2018: 22), en otras palabras, el juez bajo ningún supuesto puede valorar las características personales del testigo para valorar la credibilidad. Solo el análisis del testimonio permite determinar la correspondencia entre los hechos y los recuerdos.

El principal desacuerdo intersujeto radica en la identificación de personas (Manzanero, 2008: 180), basta que un testigo identifique a una persona como supuesto responsable del hecho delictivo, la versión de los demás testigos serán calificados como elemento corroborrador, sin embargo, por más que exista puntos de coincidencia en sus testimonios deben ser tomados como un dato objetivo, puesto que pueden llevar a identificaciones sesgadas, prueba de ello es el estudio recogido por (Ferrer; Dieuzeide, 2018) del año 2,014 donde han demostrado que la totalidad de declaraciones de los testigos que habían identificado en forma inequívoca a los acusados de haber sido autores de los delitos cometidos el $40 \%$ ha dado a lugar a condenas erróneas, pese a que los testigos en forma categórica han señalado estar seguros de lo que han manifestado.

Lo descrito ocurre debido a que todavía los jueces tienen el pensamiento de que dos testigos no pueden mentir sobre un mismo hechos; lamentablemente esta forma de otorgar la credibilidad, conduce a muchos errores judiciales, tal como sucedió en los casos de Rafael Ricardi Robles, condenado a 18 años de prisión por el delito de violación sexual que no cometió y Julio Robles, condenado a 5 años por el delito de robo

10 La mentira, además, implica un juicio moral. Esto es, una persona miente deliberadamente aporta una información de la que sabe conscientemente que no se ajusta a la "realidad" de los hechos (Masip, Garrido y Herrero (2004 a) (Cfr. Manzanero, 2008: 178). 
con violencia, quienes han recobrado su libertad luego de muchos años; sentencias que se fundaron en "la identificación sesgada de [presuntos culpables], presumiendo que los testimonios [de dos o más testigos] son creíbles puesto que concuerdan [en sus afirmaciones" (Joaquin; Diges, 1991: 50). Esto es, previo a la identificación en rueda los fiscales o policías muestran fotografías de los posibles responsables del hecho delictivo, generando de este modo sesgos en la identificación.

El hecho de que exista puntos de coincidencia entre las versiones no es sinónimo de veracidad, así como la presencia de inconsistencias periféricas es un signo de que todos los testigos mientan, sino que esto obedece a la capacidad de percepción de la memoria (Nieva, 2010: 228); por ello, el juez a la hora de valorar las corroboraciones periféricas tiene que describir de cuáles son esos elementos que merecen ser valorado como elementos corroborrador y que extremo del objeto de prueba ha corroborado, asimismo, cuando valora la credibilidad testimonial de los testigos tiene que describir en la motivación de la sentencia del porque dicha versión de tal o cual testigo es creíble y por qué no, para cuyo efecto debe recurrir a los criterios antes señalados.

\subsubsection{LOS COMENTARIOS OPORTUNISTAS O PERSONALES COMO CUARTO PASO DE LA EVALUACIÓN DE LA CREDIBILIDAD}

Los comentarios oportunistas son aquellos comentarios personales que generalmente "pretenden beneficiar a una de [las hipótesis objeto del proceso]" (Nieva, 2010: 229) corchete agregado, en otras palabras, buscan maximizar o minimizar la magnitud del hecho que ha percibido a través de sus sentidos o sencillamente el declarante entrega una porción de información irrelevante fuera del contexto.

Los comentarios personales de los testigos contienen datos desorganizados en su estructura, ya que están basados en creencias o estereotipos sociales y culturales ${ }^{11}$, "aspectos que desde luego restan la credibilidad del contenido de una declaración testimonial” (Manzanero;

11 Los estereotipos sociales y culturales están establecidos por creencias, ideas, prejuicios, opiniones, etc., preexistentes dentro de un ámbito social cultural que se practica en forma generalizada. 
Diges, 1993: 21), estos comentarios oportunistas no solamente restan la credibilidad del testigo, sino quita por completo la objetividad, ya que está orientado a beneficiar al acusado o a la víctima; caracteres que nos demuestra la parcialidad con uno de los sujetos procesales,

Con lo dicho no estamos pretendiendo que los testigos que tienden a maximizar o minimizar la información deban ser excluidos como órganos de prueba, sino lo que estamos advirtiendo es que dichos comentarios deben ser descritos en la motivación de la sentencia donde se debe justificar conjuntamente con los demás criterios antes señalados, es decir, debe justificar del por qué no es creíble su testimonio y por qué sí.

Finalmente, debemos precisar que con los pasos o criterios antes señalados en modo absoluto estamos diciendo que sea los únicos medios mediante las cuales se debe evaluar la credibilidad testimonial de los testigos, sino lo que estamos diciendo es que estos pasos deben ser tenidos en cuenta como datos objetivos para examinar la credibilidad testimonial, por lo que, su valoración se debe realizar conjuntamente con otros elementos de juicio, "puesto que la prueba testifical, por si sola, si no es corroborada por otras pruebas, es muy débil y otorga un grado de confirmación muy bajo o casi nulo”. (Ramos, 2018: 172).

\subsection{TESTIGO DE REFERENCIA O DE OÍDAS}

Es aquella persona que toma conocimiento sobre la ocurrencia de un evento criminal a través de otra persona o en forma indirecta. En la actualidad viene generando grandes problemas en el proceso penal, muchas veces el Ministerio Fiscal ante la falta de testigos presenciales recurren a testigos referenciales, con la finalidad de probar su hipótesis fiscal ante el juez de juzgamiento, sin embargo, este último no valora como prueba fiable para condenar al acusado; pese a que "[el] testigo de oídas quien, en lugar de una percepción original y directa, escuchó un relato de una persona sabedora de un acontecimiento" (De La Rua, 1991).

El problema del fondo viene a ser en la calidad de información que proporciona el testigo referencial, ya que éste en ningún momento ha tenido la oportunidad de experimentar o percibir los sucesos del 
evento fenomenológico, sino únicamente conoce una parte de la historia manipuladas o tergiversadas porque alguien lo ha contado o simplemente ha escuchado decir o hablar a alguien sobre el hecho fenomenológico; motivo por el cual su testimonio no es de todo confiable, sino por el contrario genera cierta desconfianza, ya que este testigo "no puede describir el contexto periférico de [tiempo y espacio]" (Nieva, 2010: 279) corchete agregado.

Por su parte, la doctrina dominante es unánime en señalar que el relato del testigo de 'oidas' no es confiable debido a que no estuvo en el lugar de los hechos, por ello su testimonio es débil en su credibilidad, de modo que por sí mismo "ni siquiera ayude el hecho de recurrir a los datos de la coherencia del relato o a las corroboraciones periféricas [del hecho fenomenológico]" (Nieva, 2010: 279), cursiva agregado; debido a que la historia que reproduce este testigo es un relato que ha sido contado por una tercera persona, de modo tal que, es difícil detectar la mentira de si el testigo referencial está mintiendo o no, ya que el que cuenta pudo haber añadido, modificado o mentido al receptor sobre lo que ha percibido.

\subsubsection{CRiterios para eValuar la CRedibiLidAd del testimonio Referencial}

Hoy en día los jueces de juzgamiento sostienen que la declaración de los testigos de referencia como únicas pruebas no son fiables para condenar a los acusados ya que consideran como inidónea ${ }^{12}$, toda vez que solo sirve para corroborar o ayudar a aclarar un hecho; en el mismo sentido la Sala Penal Transitoria-Lima, ha dicho que a la declaración de los testigos de referencia -oídas - no se le puede dar credibilidad; razón por el cual no se puede constituir como única prueba para condenar ${ }^{13}$. Este argumento se funda en que no se puede determinar si realmente el testigo de oídas está diciendo la verdad o está mintiendo.

El problema radica en el momento de la recepción de la información por parte del testigo de oídas. Esto es, cuando el emisor -por ejemplo, la víctima o el testigo presencial- transmite la información al receptor;

12 R.N. 173-2012, Cajamarca, 22 enero del 2013.

13 R.N. 73-2015, Lima, de 20 de setiembre del 2016.

Rev. Bras. de Direito Processual Penal, Porto Alegre, v. 6, n. 1, p. 453-480, jan.-abr. 2020. 
lapso en que el receptor reinterpreta la información trasmitida a su antojo y se crea en la mente una historia transformada o distorsionada, pero también puede suceder lo contario, es decir el testigo puede almacenar la información fiel reflejo de lo que ha oído, es por ello que es muy complejo examinar la credibilidad del testimonio del testigo de oídas.

Frente a esta situación en la práctica judicial los jueces han recurrido a los criterios de coherencia, persistencia en la incriminación, verosimilitud, ausencia de incredibilidad subjetiva, para examinar la calidad del testimonio, pero estos criterios no son muy seguros para evaluar la credibilidad del testimonio de un solo testigo referencial, debido a que es perfectamente posible que un testigo de oídas puedas narrar los hechos en forma coherente, persistente hasta puede resultar verosímil lo que está diciendo, "pero cuando el testigo contradice no es posible saber si alguna de la información en conflicto es verdadera o ninguna; y si alguno de la información es verdadera”. (Ramos, 2018: 137).

El asunto cambia por completo cuando llevamos los criterios de coherencia, persistencia en la incriminación, verosimilitud, ausencia de incredibilidad subjetiva, la contextualización y la corroboración periférica, para examinar la credibilidad de "pluralidad de testigos de referencia", todas ellas de procedencias distintas o de orígenes distintos, es decir, que entre los testigos no exista ningún tipo de vínculo de parentesco por consanguíneo o por afinidad, que pueda restar la credibilidad subjetiva ${ }^{14}$ del testimonio y que por el contario cada uno de los datos ofrecidos por los testigos de oídas, corroboren lo dicho por el otro en forma verosímil.

Bajo estos criterios consideramos que si es posible sustentar una condena al acusado, tal como lo hizo el Tribunal Supremo Español en la sentencia ${ }^{15}$ donde ha valorado como únicas pruebas de condena,

14 Acuerdo Plenario N² 2-2005-/CJ-116 de fecha 30 de septiembre del 2005.

15 STS 2810/2019, de 13 de marzo de 2019, España. En donde, ha señalado que "los testimonios de referencia aquí no suplen el testimonio directo de la agresión, pero sí prueban, en cuanto testimonios sobre lo percibido por el testigo, que aquélla persona les contó voluntariamente un suceso que ellos escucharon; y ese hecho de su narración o relato unido a la demostración de las lesiones sufridas mediante la pericial médica acreditativa de la veracidad de lo relatado, constituye la prueba de cargo que justifica el hecho probado de la Sentencia de instancia”. (Cfr. Fj. Tercero). 
las versiones de dos testigos referenciales de origines distintas, quienes han relatado los hechos contados por la víctima de manera coherente, persistente, contextualizada, con ausencia de incredibilidad subjetiva, las mismas que han sido corroboradas con otros datos objetivos. Este criterio ha sido adoptado en diferentes sentencias ${ }^{16}$. Por su parte, el Tribunal Europeo de Derecho Humanos (TEDH) en el caso ${ }^{17}$, sugirió a los tribunales que en los casos donde existan únicamente testigos referenciales que fundan una condena los jueces deben examinar su fiabilidad con un procedimiento minucioso; por nuestra parte consideramos que los procedimientos adecuados para examinar la fiabilidad deben ser los criterios de coherencia, contextualización, ausencia de incredibilidad subjetiva, corroboración periférica y verosimilitud, las mismas que deben estar apoyados con la versión de pluralidad de testigos de orígenes distintos.

\section{Consideraciones finales}

En los argumentos precedentemente señalados hemos podido advertir que la memoria tiene la función de captar, almacenar y recordar una parte de lo que percibe sus sentidos; estando así la memoria, a la hora de efectuar la reconstrucción del relato fáctico exterioriza únicamente una

16 STS 821/2009 de 29 de junio del 2009, STS 246/2016 de 28 de junio del 2016, STS 64/2005 de 9 de mayo de 2005; las mismas que tiene un antecedente común en las sentencias de (STS de 12 de julio de 1996 y STS de 10 de febrero de 1997).

17 Al-Khawaja y Tahery v. Reino Unido, donde ha precisado que "[D]onde una declaración de oídas o referencial es la única o decisiva evidencia contra el acusado, su admisión como prueba no resulta automáticamente en una violación al artículo 6.1. Al mismo tiempo, cuando la condena está basada única o decisivamente en la evidencia de un testigo ausente, el tribunal debe sujetar los procedimientos al más minucioso escrutinio. Por los peligros de la admisión de tal evidencia, constituye un factor muy importante para ponderar en la balanza [...], y uno que requeriría suficientes factores de contrapeso, incluida la existencia de fuertes salvaguardas procedimentales. La cuestión en cada caso es saber si hay suficientes factores corroborativos, incluyendo medidas que permitan una justa y propia evaluación de la fiabilidad de la evidencia. Esto permitiría que una condena se base en tal evidencia sólo si es suficientemente fiable dada su importancia en el caso" (cfr. párr. 147)”. 
parta de la información almacenada en la memoria episódica, muchas veces con serios errores, por la presencia del trascurso del tiempo, sugestión y la autosugestión, que contaminan y modifican las huellas de la memoria.

La calidad de la información que proporciona el testigo presencial dentro del proceso penal no es de todo exacto, puesto que la memoria episódica no registra como huella de memoria de todo lo que ha percibido sensorialmente, sino una parte de ella. La correcta valoración de la credibilidad testimonial de los testigos directos se debe partir examinando la correspondencia entre los hechos y lo que recuerda el testigo, para cuyo efecto el juez debe tener en cuenta como dato objetivo la coherencia del testimonio, la contextualización, la corroboración periférica y los comentarios oportunista o personales, las mismas que deben estar siempre apoyados con otros elementos de juicio que deben estar descritos en la motivación de la sentencia.

En tanto, la credibilidad testimonial de los testigos de referencia únicamente puede fundar una condena si solo sí exista pluralidad de testigos referenciales de orígenes distintos y que su testimonio sea coherente, contextualizada, con ausencia de incredibilidad subjetiva, corroborada con pruebas periféricas y que resulte verosímil, las mismas que deben estar apoyados con otros datos objetivos.

Por otro lado, la prueba testifical por sí sola, no obedece a los estándares de la prueba, por lo que, siempre debe ser valorada conjuntamente con otros elementos de juicio actuada en el plenario bajo las reglas del contradictorio, solamente así una condena estará justificado plenamente.

\section{Referencias Biblográficas}

ALONSO, H. Los policías como detectores del engaño: investigación en torno al efecto de sesgo del investigador. Universidad de Salamanca, Salamanca, España, 2009.

ALONSO-QUECUTY, M. Memoria autobiográfica: La influencia de los estados de ánimo sobre las perspectivas del recuerdo. Estudios de psicología, 43-44, 5-18. 1990.

ATKINNSON, R. y SHIFFRIN, R. (1983) Human memory. A proposed system and its control processes. En: K. W. Spence y J.T. spence (eds.). The psychology of learning and motivation: advances is research and theory. Nueva York: Academic 
press (trad. cast. En M.V. Sebastián [comp]. Lecturas de psicología de la memoria, Alianza Universidad textos, 1983.

BADDELEY, Alan. Memoria Humana- teoria y práctica. Editorial Mcggraw-Hill. S.A., 1998.

BAYTELMAN, Andrés y DUCE, Mauricio. Litigación penal jucio oral y prueba. Grupo Editorial Ibáñez.Colombia, 2016.

BLANSHARD, Brand. Coherence as the Nature of Truth. Cambridge: In Michael Lynch (ed.), The Nature of Truth: Classic and Contemporary Perspectives, the mit press, 2001.

CABEZA, Roberto y KIM, Hongkeun. Trusting our memories: dissociating the neural correlates of confidence in veridical versus illusory memories. Joun of Neuroscience $\mathrm{N}^{\circ}$ 27(45):12190 -12197. 2007. https//doi.org/10.1523/ jneurosci.3408-07.2007

CHARLES, Morris y ALBERTH, Maisto. Psicología. Trad. Ortiz Elena. Universidad de Carolina del Norte, Campus Charlotte, 2009.

DE LA RUA, Ferreyra. Teoría General del Proceso. Tomo I. 2da edición, 1991.

DIGES, Margarita. Testigos, sospechosos y recuerdos falsos. 1ra reimpresión. Madrid, Editorial Trotta, 2018.

DIGES, Margarita. La utilidad de la psicología del testimonio en la valoración de pruebas de testigos. Aequitas, Revista cuatrimestral del poder judicial del Estado de Sinaloa, $N^{\circ} .5$, año 3. 2014, p. 17.

DI GESU, Cristina. Prova penal e falsas Memórias. Rio de Janeiro. Lumen Juris, 2010. FERRER, Francisco; DIEUZEIDE, María. Psicología del testimonio: los siete pecados de la memoria en testigos y víctimas. Revista Pensamiento Penal. Argentina, 2018. HAACK, Susan. Evidencia e Investigación: Hacia la construcción en epistemologia. Trad. Martinez, Angeles. Madrid: Editorial Tecnos, S.A. 1993.

HAACK, Susan. Toda la verdad y nada más que la verdad. Midwest Studies in Philosophy, XXXII, 2008 Trad. Santacoloma, Andrés y Vázque, Carmen. Doxa 35, 2012, p. 571-587.

HEIDEGGER, Martín, ¿Qué significa pensar?. Trad. Gabás Raúl. Madrid, Editorial Trotta, 2005.

HOFFDING, Harald. Bosquejo de una Psicología Basada en la Experiencia. Editorial Daniel Jorro editor, Madrid, 1926. 
IZQUIERDO, Iván. Memoria. 2a.ed.rev..e ampl. ed. Porto Alegre-Brasil: ArtMed, 2011.

JAUCHEN, Eduardo. Tratado de la prueba en materia penal, Rubinzal-Culzoni Editores, 2014.

JOHNSON, M. y RAYE, C. Reality Monitoring vs. Discriminating Between External. Bullerin of the Psyconomic Society, 15(6), 1980, p. 405-408.

JOHNSON, M. y RAYE, C. Reality monitoring. Psichological Review, 88, 1, 67-8. 1981.

LIPTON'S, Peter. The Epistemology of Testimony. The History and Philosophy of Science, 2001, p. 1-31, 1998.

LINDSAY, R., Lim, Robert, Marando, Louis, y Cully, Deborah. Mock-juror evaluations of eyewitness testimony: a test of metamemory hypothesis. Journal of Applied Social Psychology, 16, 1986, p. 447-459. https://doi.org/10.1111/j.1559-1816.1986. tb01151.x

LOFTUS, Elizabeth. Creating False Memories. Scientific American, 277(3), 1997, p. 70-5. http://doi.org/10.1038/scientificamerican0997-70

LOFTUS, Elizabeth. Recordando peligrosamente. En: el Escéptico. N 9. Trad. Iñaki Camiruaga. Edita ARP - sociedad para el avance del pensamiento crítico. España, 2000, p. 31.

MANZANERO, Antonio. Realidad y Fantasía: Credibilidad, Metamemoria y Testimonio. 1991. http://doi.org/10.13140/2.1.1923.6808

MANZANERO, Antonio. Procedimientos de evaluación de la Credebilidad de las declaraciones de menores víctimas de agresiones sexuales. Psicopatología Clínica, Legal y Forense, Vol. 1, No 2. 2001, p. 51-71.

MANZANERO, Antonio. Psicología del testimonio: Una aplicación de los estudios sobre la memoria. Ediciones Pirámide, 2008.

MANZANERO, Antonio. Memoria de Testigos: Obtención y valoración de la prueba testifical, Editorial Piramide, 2010.

MANZANERO, Antonio y DIGES, Margarita. Evaluación subjetiva de la exactitud de las declaraciones de los testigos: la credibilidad. Anuario de psicología jurídica, 3 (1), 1993, p. 7-27.

MANZANERO, Antonio y ROCIO, M. El recuerdo de hechos traumáticos: exactitud, tipos y características. Cuad Med Forense;18 (1), Madrid, 2012, p. 19-25 https:// doi.org/10.4321/S1135-76062012000100003 
MAZZONI, Giuliana. Psicología del testimonio. Trad. Moreno, Amparo. Madrid: Editorial Trotta. 2019.

MEMON, Amina, VRIJ, Aldert y BULL, Ray, Psychology and Law: Truthfulness, Accuracy and Credibility, Editorial John Wiley \& Sons Ltd, 2003.

MIRA, Joaquín y DIGES, Margarita. Teorías intuitivas sobre memoria de testigo: un examén de metamemoria. Revista de Psicología Social, 6 (1), 1991, p. 47-60. https://doi.org/10.1080/02134748.1991.10821635

NIEVA, Jordi. Valoración de la prueba. Madrid. Editorial Marcial Pons, 2010.

NEISSER, Ulric. Cognitive psychology, Nueva York. Appelton -Century- Croff, 1967.

NORONHA DE ÁVILA, G. Falsas Memórias e Sistema Penal: A prova testemunhal em xeque: Lumen Juris. Rio de Janeiro, 2013.

OFFE, Heinz. El dictamen sobre la credibilidad de las declraciones de testigos. Credibility assessment of witness testimony. Anuario de psicologia jurídica, 2000, p. 11-23.

PETISCO, José. La susceptibilidad de la memoria de un testigo. Cuadernos de la Guardia Civil No 53. 2016, p. 78-95.

QUEREJETA, Luis. Validez y credibilidad del testimonio. La psicologia forense experimental. Eguzkilore: Cuaderno del Instituto Vasco de Criminología $\mathrm{N}^{\circ} 13$. 1999, p. 157 - 168. http://hdl.handle.net/10810/25430

RAMOS. Vitor. Prova Testemunhal: Do subjetivismo ao objetivismo, do isolamento cientifico ao dialogo co a psicologgia e a epistemologia. Porto Alegre e Valencia: Universidade Federal Do Rio Grande Do Sul e Universitat de Girona, 2018.

SCHOOLER, Jonathan, Gerhard, Delia. y Loftus, Elizabeth. Qualities of unreal. Journal of Experimental Psychology: Learning, Memory and Cognition, 12, 171181, 1986. http://dx.doi.org/10.1037/0278-7393.12.2.171

SEQUIRE, L. y COHEN, N. Human memory and amnesia. EnG. Lynch, J. McGaugh y N. M. Weinberg (eds). Neurobioñogy of Learning and Memory.Nueva York. Guilford Pres, 1984.

STEIN, Lilian Milnitsky; ÁVILA, Gustavo Noronha de. Avanços científicos em psicologia do testemunho aplicados ao reconhecimento pessoal e aos depoimentos forenses. Brasilia: Disponível em Série Pensando o Direito, Nº 59. 2015.

TULVING, Endel. Elements of episodic memory, Oxford clarendon press, 1983. 
TULVING, Endel. Episodic and semantic memory. En: Endel Tulving y W. Donaldson (eds). Organizatión of memory. Nueva York: Academic Pres, 1972.

VALVERDE, María, RUIZ, José Antoni y LLOR, Bartolomé. Valoración de la Credibilidad del Testimonio: Aplicación del Modelo Reality Monitoring. Revista Internacional de Psicología, 2013. https://doi.org/10.33670/18181023.v12i02.68

WELLS, G. y LINDSAY, R. How do people infer the accuracy of eyewitness memory? Studies of performance and a metamemory analysis. En: Sally. Lloyd-Bostock y B. Clifford (Eds.) Evaluating witness evidence, Recent Psychological research and new perspectives. Nueva York: John Wiley \& Sons, 1983.

\section{Informações adicionais e declarações dos autores (integridade científica)}

Agradecimentos (acknowledgement): a Rossmery Tineo, por su apoyo incondicional, en la corrección del presente artículo.

Declaração de conflito de interesses (conflict of interest declaration): el autor confirman que no existen conflictos de intereses en la realización de la investigación y redacción de este artículo.

Declaração de autoria e especificação das contribuições (declaration of authorship): todas y solo las personas que cumplen con los requisitos de autoría de este artículo se enumeran como autores; todos los coautores son totalmente responsables de este trabajo en su totalidad.

Declaração de ineditismo e originalidade (declaration of originality): el autor asegura que el texto publicado aquí no ha sido publicado previamente en ningún otro medio y que la futura republicación solo ocurrirá con la indicación expresa de la referencia de esta publicación original; también atestigua que no hay plagio de terceros o auto-plagio. 
Dados do processo editorial

(http://www.ibraspp.com.br/revista/index.php/RBDPP/about/editorialPolicies)

- Recebido em: 17/05/2019 Equipe editorial envolvida

- Controle preliminar e verificação de plágio: 05/07/2019

- Avaliação 1: 16/07/2019

- Editor-chefe: 1 (VGV)

- Revisores: 3

- Avaliação 2: 18/07/2019

- Avaliação 3:19/07/2019

- Decisão editorial preliminar: 22/07/2019

- Deslocamento ao V6N1 e aviso autor: 22/07/2019

- Retorno rodada de correções 1: 31/08/2019

- Decisão editorial 2: 09/12/2019

- Retorno rodada de correções 2: 21/12/2019

- Decisão editorial final: 22/12/2019

\section{COMO CITAR ESTE ARTIGO:}

AYALA YANCCE, Rafael. Credibilidad testimonial del testigo en el proceso penal. Revista Brasileira de Direito Processual Penal, Porto Alegre, vol. 6, n. 1, p. 453-480, jan./abr. 2020.

https://doi.org/10.22197/rbdpp.v6i1.246

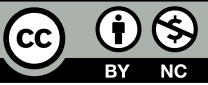

Esta obra está licenciada com uma Licença Creative Commons Atribuição-NãoComercial 4.0 Internacional. 